\title{
MIND MGMT: PARANOID NIGHTMARES OF A FUGITIVE REALITY
}

\author{
Pepe Rojo \\ University of California San Diego \\ rojopepe@hotmail.com
}

Recibido: 16-12-2016

Aceptado: 15-04-2017

\begin{abstract}
(a) (1)
Abstract

From 2012 to 2015, Matt Kindt created Mind MGMT, an ultra-paranoid world filled with mental hermaphrodites, children books and pop records that cause riots and revolutions and psychic snipers, all woven together through the elusive Mind Management program. Kindt re-creates fictionally both the breakdown of coherence and the fragmented narratives that make up life in the globalized 21st. century, where permanent crisis seems to be the current state of affairs. Kindt uses several devices to achieve this: fragmented and parallel narrative sequences, scaffolded and nested plot turns, fake ads and field guides. At the same time, Kindt draws on several genres and formats that use the search/production of both truth and reality as their dramatic engine: crime/espionage novels, conspiracy theories, investigative journalism and procedure manuals. This experimental comic/essay focuses on how the radical devices Kindt uses in creating Mind MGMT tap into the paranoid desire and fear of finding out how reality is produced, at the same time playing with the materiality and self-reference of the quotes it uses, drawing on scanned images of the comic itself.
\end{abstract}

KEYWORDS: media, mind mgmt, matt kindt, reality, genres.

\section{REFERENCES}

All images were taken from Matt Kindt's Mind MGMT, published in six volumes by Dark Horse Books (2012-2015). All artwork is Matt Kindt's.

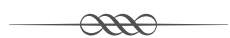




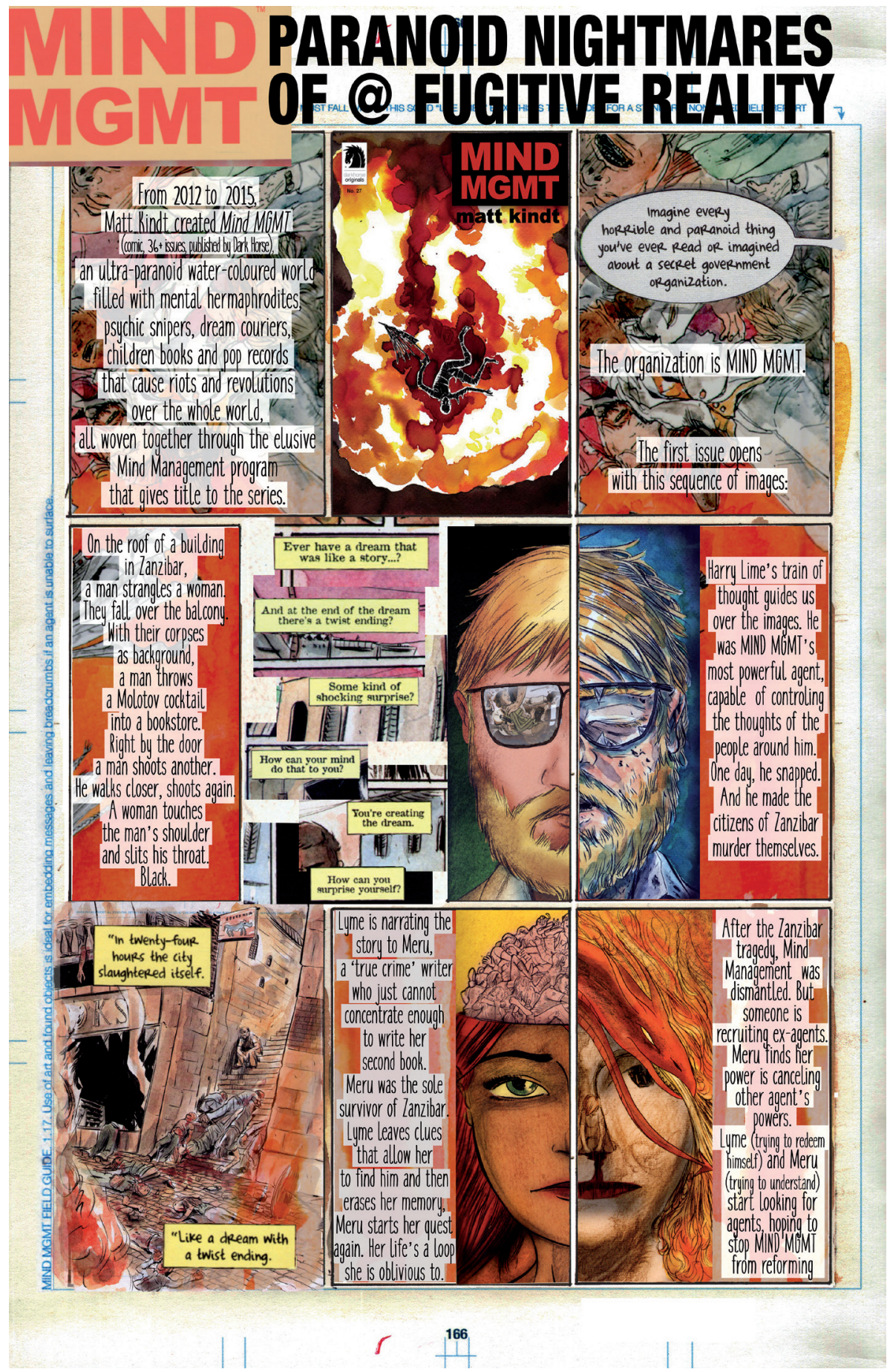


PAge 1

Background: Mind MGMT \#28 (2014), Cover.

Panel 2: Mind MGMT \#27 (2014), Cover.

Panel 3: http:/ / www.nytimes.com/2016/11/20/opinion/the-secret-agendaof-a-facebook-quiz.html?_r=1

Panel 5: Mind MGMT, Vol. 1: The Manager (2013), pp. 11-14.

Panel 6: Mind MGMT \#5 (2012), Cover.

Panel 7: Mind MGMT \#31 (2014), Cover.

Panel 8: Mind MGMT, Vol. 1: The Manager (2013), p. 129.

Panel 9: Mind MGMT \#1 (2012), Cover.

Panel 10: Mind MGMT \#3 (2012), Cover.

Panel 12: http:/ / www.nytimes.com/2016/12/06/us/fake-news-partisan-republican-democrat.html

Field guide: Mind MGMT, Vol. 1: The Immortals (2013), p. 26. 


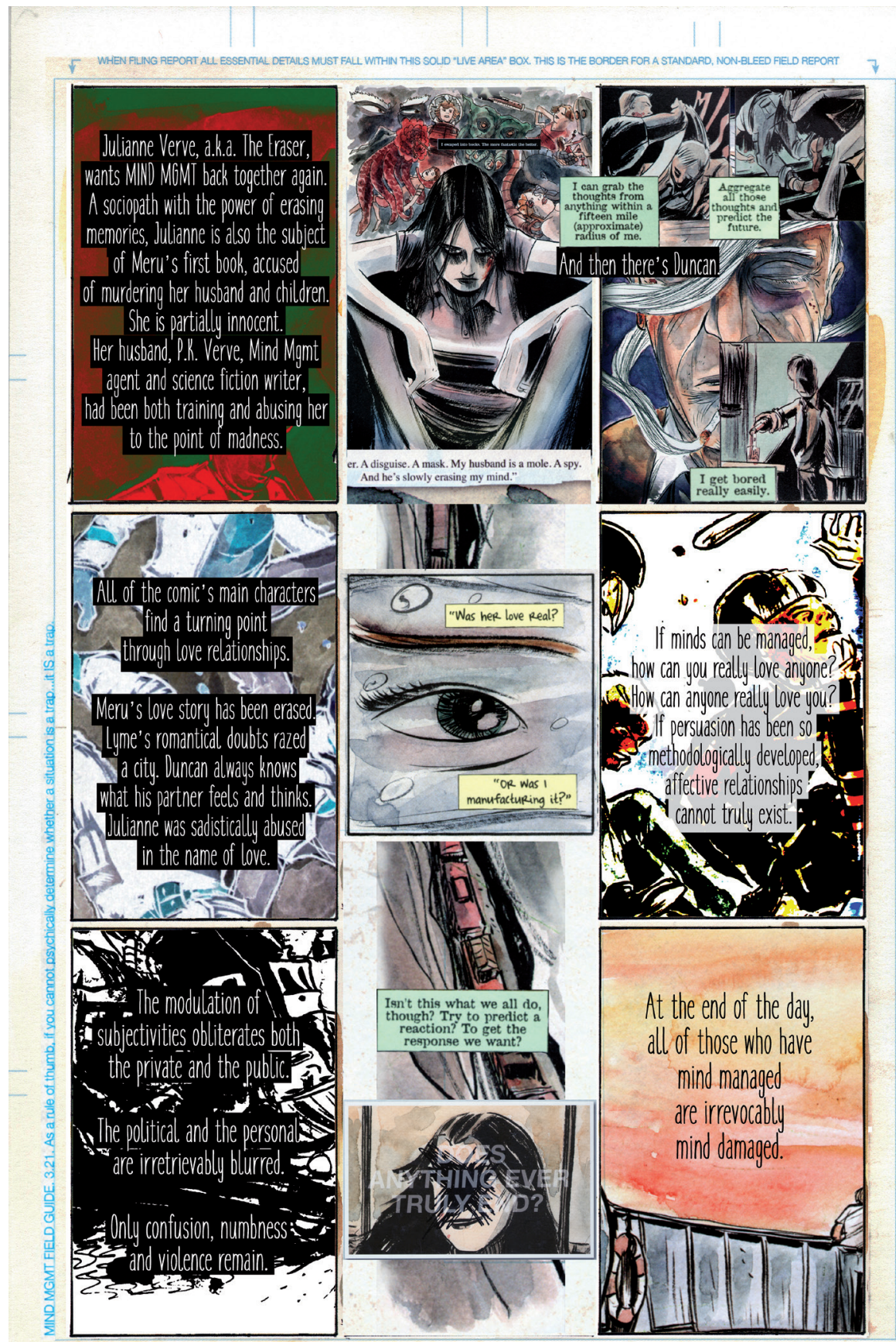

Therapy Session 018: Subject is increasingly delusional. Fantasy scenarios are typical. Believes she is a "superagent." 
PAge 2

Background: Mind MGMT, Vol. 5: The Eraser (2015), p. 18.

Panel 2: Mind MGMT, Vol. 3: The Home Maker (2014), p. 92.

Panel 2: Mind MGMT \#9 (2013), p. 22.

Panel 3: Background: Mind MGMT \#23 (2014), Cover.

Subpanels: Mind MGMT \#10 (2013), pp. 4-5.

Panel 4: http:/ /yeslab.org/un-celebrates-420

Panel 5: Mind MGMT, Vol. 1: The Manager (2013), p. 108.

Panel 8: Mind MGMT, Vol. 6: The Immortals (2016), Back cover.

Dialogue: Mind MGMT \#10 (2013), p. 9.

Panel 9: Mind MGMT, Vol. 4: The Magician (2014), p. 169.

Field guide: Mind MGMT, Vol. 3: The Home Maker (2014), p. 14.

Footer: Mind MGMT, Vol. 4: The Magician (2014), p. 12. 


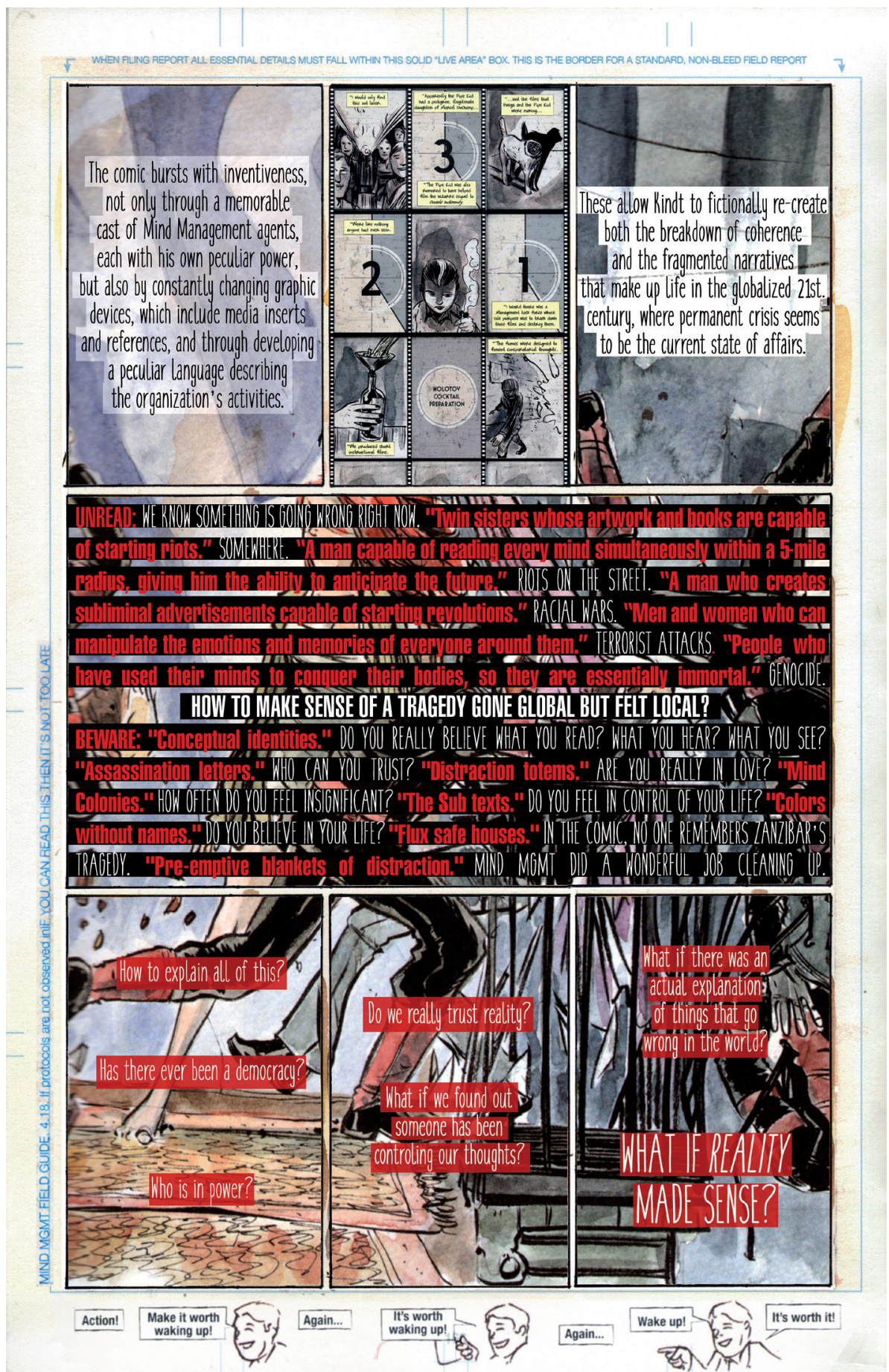


PAge 3

Background: Mind MGMT, Vol. 5: The Eraser (2015), p.19.

Panel 1: http://www.huffingtonpost.com.mx/entry/comet-pizza-conspiracy-theory-fake-news_us_5844a17de4b09e21702f486c

Panel 2: Mind MGMT, Vol. 4: The Magician (2014), pp. 109-110.

Panel 4: First paragraph, red font: James Kaplan, «Mind MGMT by Matt Kindt», Panel Patter, October 27, 2014. http://www.panelpatter.com/2014/10/ Mind-mgmt-by-matt-kindt-series-review.html

Panel 7: http://boingboing.net/2016/08/25/scarfolk-win-your-human-right.html

Field guide: Mind MGMT, Vol. 1: The Manager (2013), p. 106.

Footer: Mind MGMT, Vol 3: The Home Maker (2014), p. 15. 


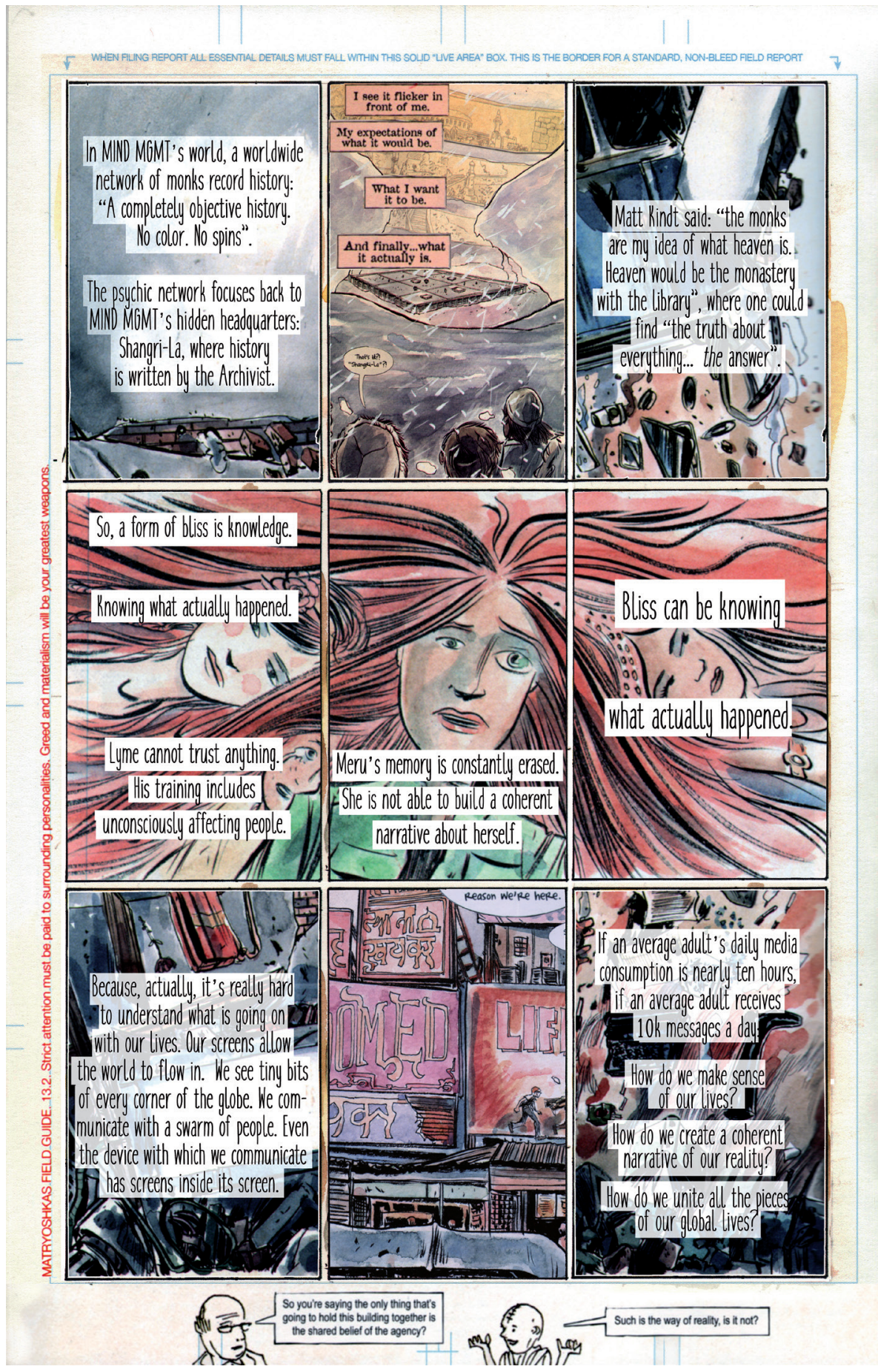


PAge 4

Background: Mind MGMT \#24 (2014), Back cover.

Panel 2: Mind MGMT \#11 (2013), p. 19.

Panel 3: Abraham Riesman, «Talking to Mind MGMT Creator Matt Kindt About Spies and Hard-core Pornography», Vulture: Devouring Culture, November 21, 2014.

http:/ / www.vulture.com/2014/11/Mind-mgmt-matt-kindt-comics.html

Panel 4, 5, 6: Mind MGMT \#12 (2013), p. 12.

Panel 7: http://www.newyorker.com/news/news-desk/the-real-paranoiainducing-purpose-of-russian-hacks

Panel 8: Mind MGMT, Vol. 4: The Magician (2014), pp. 158-159.

Field guide: Mind MGMT, Vol. 3: The Home Maker (2014), p. 14.

Footer: Mind MGMT, Vol. 6: The Immortals (2016), p. 145. 


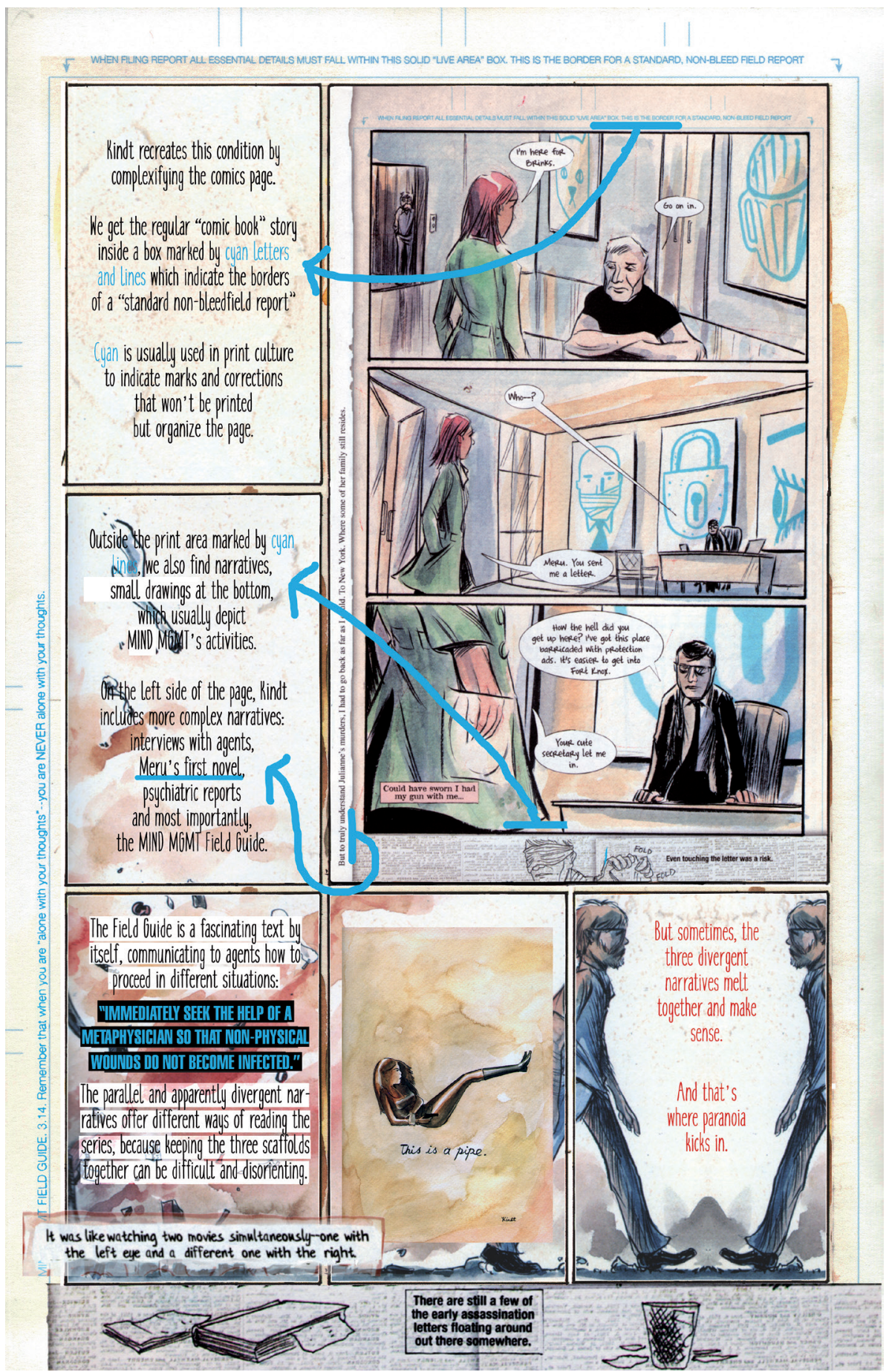


PAge 5

Background: Mind MGMT \#24 (2014), Cover.

Panel 2: Mind MGMT \#7 (2012), p. 7.

Panel 3: https://www.theguardian.com/technology/2016/dec/02/facebook-fake-news-flag-techcrunch-bs-detector

Panel 5: Mind MGMT \#22 (2014), Cover.

Panel 6: http://www.npr.org/sections/alltechconsidered/2016/11/23/503 $146770 /$ npr-finds-the-head-of-a-covert-fake-news-operation-in-the-suburbs

Field guide: Mind MGMT, Vol. 1: The Manager (2013), p. 76.

Footer: Mind MGMT \#7 (2012), p. 9. 
WHEN FLING REPORT ALL ESSENTALL DETALS MUIT FAL WITHIN THIS SOLD "LIVE AREA" BOX. THIS IS THE BORDER FOR A STANDARD, NON-BLEED FELD REPORT
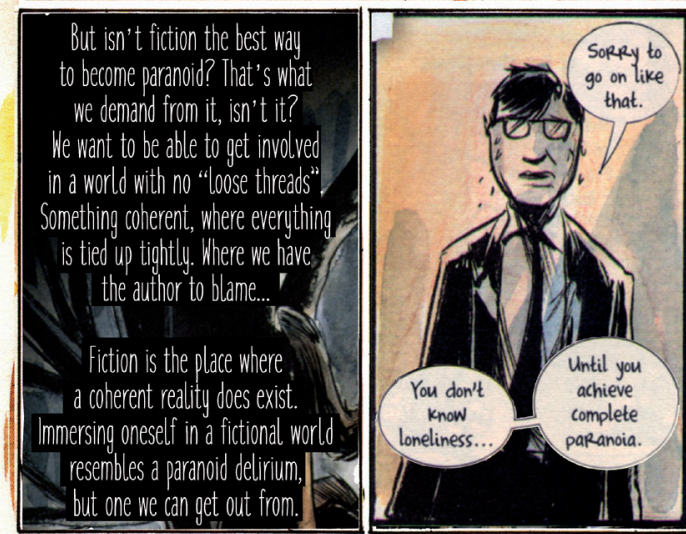

- linot takes advantage of the paranoid

aspect of fiction. The comic is filled with

references and case files, scaffolded

narratives with nested implications.

ADOPTION: Group home will

provide unconditional love.

Expenses paid. Please call!

The 'floppie' itself is pactaged as a para-

noid device: the back covers are filled

with MMOD MOMT ads, cd and book covers,

psychological profiles and questionnaires,

every detail has to be taken into account:

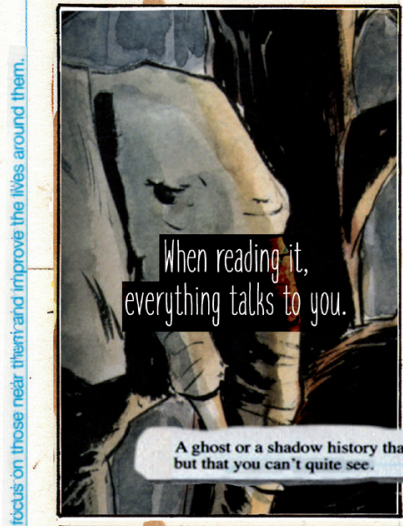

at At the same time, Kindt draws
on several genres and formats
that use the search/production
of both truth and realitu as their
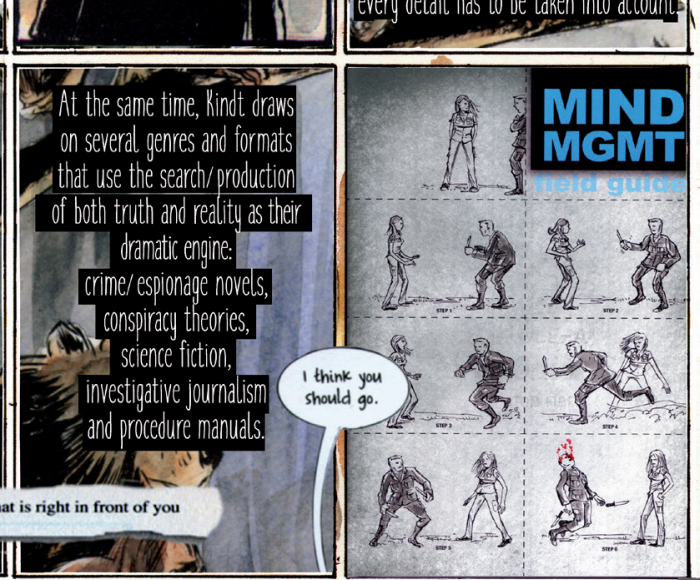

Conspiracy theories assert that

the evidence is hidden, there is a plan,

and we are being lied to.

-1 They are truing to control us.

How can you get a hold of reality in a

world that obeus espionage genre rules?

- 지

tho can y

(1) 1

$7 \mathrm{~N}$ MO

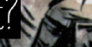

\section{9}

A MAND

a strong position towards reality. Reality is something to doubt about, but the TRUIH, complete and absolute, - A is somenhere out there.
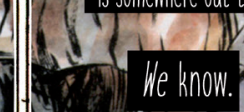

(1)

듀 OTVORDE

FROM R

TOO BROKE?

5-5-1-5-15-5-7784

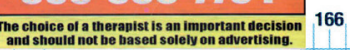

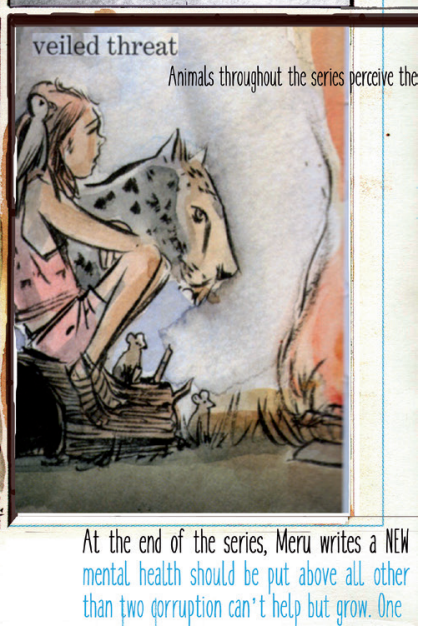


PAge 6

Background: Mind MGMT, Vol. 3: The Home Maker (2014), p. 170.

Panel 2: Mind MGMT \#7 (2012), p. 12.

Panel 3: Mind MGMT \#14 (2013), Back cover.

Panel 4: http://www.realtruenews.org/single-post/2016/08/11/FACT-

CHECK-Did-Obama-Create-ISIS

Paanel 5: Mind MGMT \#8 (2012), p. 17.

Panel 6: Mind MGMT \#26 (2014), Cover.

Panel 7, 8: Mind MGMT \#14 (2013), Back cover.

Field guide: Mind MGMT, Vol. 6: The Immortals (2016), p. 172. 


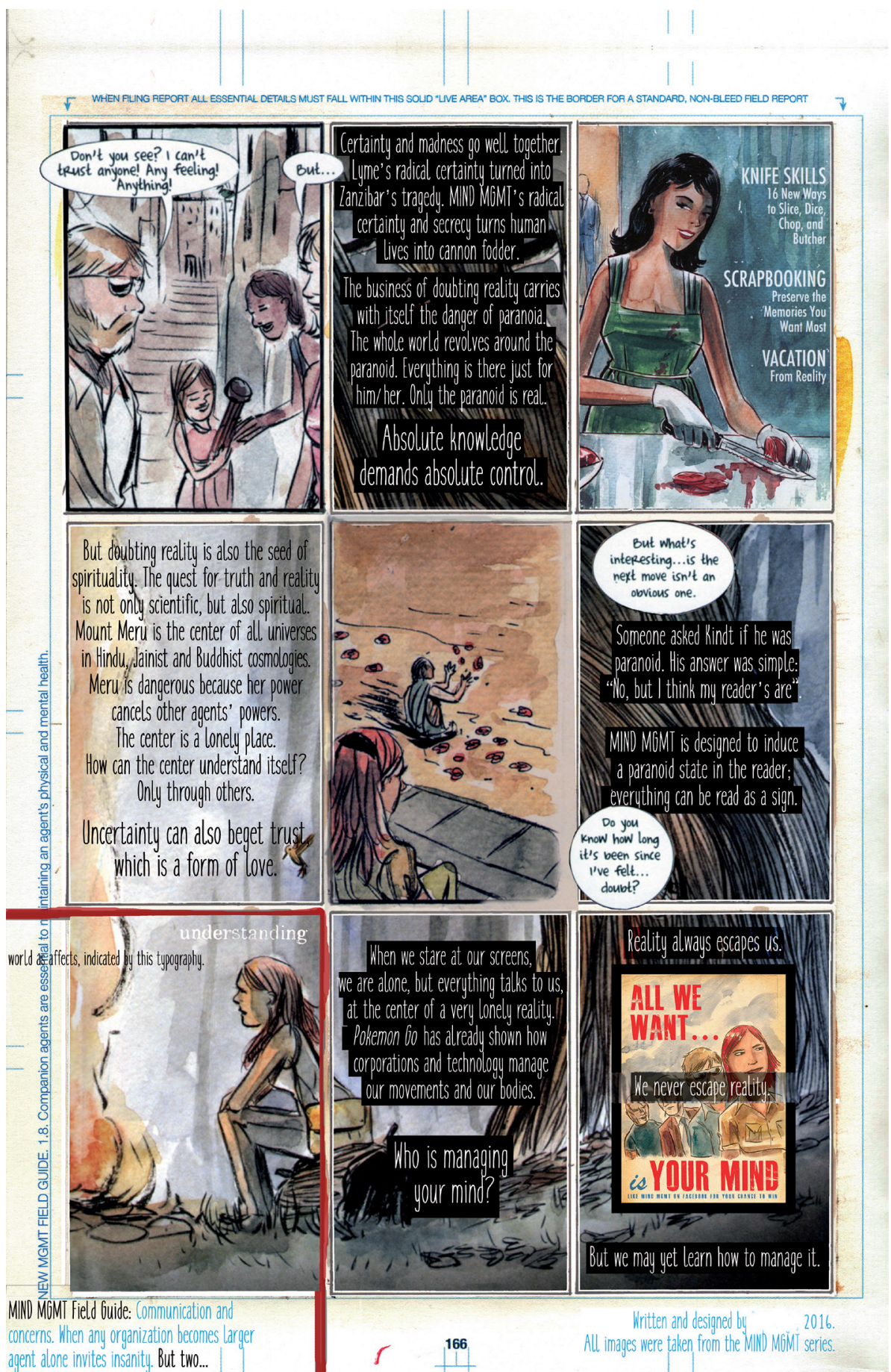


PAge 7

Background: Mind MGMT, Vol. 3: The Home Maker (2014), p. 171.

Panel 1: Mind MGMT, Vol. 1: The Manager (2013), p. 120.

Panel 3: Mind MGMT \#16 (2013), Cover.

Panel 4: http:/ /yeslab.org/pharmagreed

Panel 5: Mind MGMT, Vol. 5: The Eraser (2015), p. 25.

Panel 6: Abraham Riesman, «Talking to Mind MGMT Creator Matt Kindt About Spies and Hard-core Pornography», Vulture: Devouring Culture, November 21, 2014. http://www.vulture.com/2014/11/Mind-mgmt-matt-kindt-comics.html

Panel 9: Mind MGMT: Sorteo para aparecer dibujado en uno de los numeros de la serie de Matt Kindt, Play Reactor, August 12, 2013. https:/ / play-reactor. com/2013/08/12/Mind-mgmt-aparezcan-dibujados-en-uno-de-los-numeros-de-la-serie-de-matt-kindt/

Field guide: Mind MGMT, Vol. 6: The Immortals (2016), p. 166. 
PAge 8

Anuncio original: Mind MGMT, Vol. 4: The Magician (2014), p. 182

Panel 1 a 3: Mind MGMT, Vol. 1: The Manager (2013), p. 128.

Subtext: Mind MGMT \#10 (2013), p. 15.

Panel 4: Mind MGMT \#8 (2012), p. 15.

Subtext: Mind MGMT, Vol. 6: The Immortals (2016), p. 150.

Panel 5: Mind MGMT \#10 (2013), p. 14.

Subtext: Mind MGMT, Vol. 6: The Immortals (2016), p. 150.

Panel 6: Mind MGMT, Vol. 6: The Immortals (2016), p. 151.

Panel 7: Mind MGMT, Vol. 4: The Magician (2014), p. 127.

Subtext: Mind MGMT, Vol. 5: The Eraser (2015), p. 43.

Panel 8, Subtext: Mind MGMT, Vol. 6: The Immortals (2016), p. 88. 